\title{
Perylene Bisimide Cyclophanes: Structure-Property Relationships upon Variation of the Cavity Size
}

\author{
Jessica Rühe ${ }^{a}$ (iD) \\ David Bialas ${ }^{a}$ \\ Peter Spenst ${ }^{a}$ \\ Ana-Maria Krause ${ }^{b}$ \\ Frank Würthner*a,b (D) \\ ${ }^{a}$ Institut für Organische Chemie, Universität Würzburg, Am Hubland, 97074 \\ Würzburg, Germany

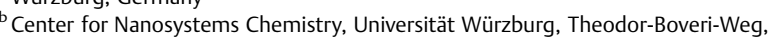 \\ 97074 Würzburg, Germany \\ wuerthner@uni-wuerzburg.de
}
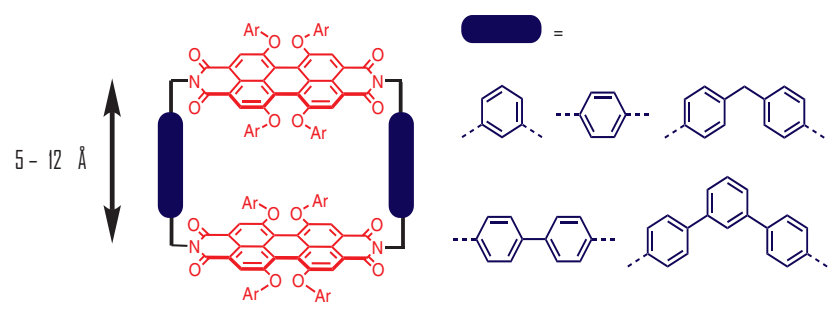

Received: 28.03.2020

Accepted after revision: 6.04.2020

DOI: 10.1055/s-0040-1709998; Art ID: 200009oa

License terms: CC

(c) 2019. The Author(s). This is an open access article published by Thieme under the terms of the Creative Commons Attribution-NonDerivative-NonCommercial-License, permitting copying and reproduction so long as the original work is given appropriate credit. Contents may not be used for commercial purposes, or adapted, remixed, transformed or built upon. (https://creativecommons.org/licenses/by-nc-nd/4.0/).

Abstract Five cyclophanes composed of two perylene bisimide (PBI) dyes and various $\mathrm{CH}_{2}$-arylene- $\mathrm{CH}_{2}$ linker units were synthesized. PM6D3H4 geometry-optimized structures and a single crystal for one of these cyclophanes reveal well-defined distances between the two coplanar PBI units in these cyclophanes, spanning the range from 5.0 to $12.5 \AA$. UV/vis absorption spectra reveal a redistribution of oscillator strength of the vibronic bands due to a $\mathrm{H}$-type exciton coupling even for the cyclophane with the largest interchromophoric distance. A quantitative evaluation according to the Kasha-Spano theory affords exciton coupling strengths ranging from $64 \mathrm{~cm}^{-1}$ for the largest cyclophane up to $333 \mathrm{~cm}^{-1}$ for the smallest one and a surprisingly good fit to the cubic interchromophoric distance in the framework of the point-dipole approximation. Interchromophoric interaction is also noticed in fluorescence lifetimes that are significantly increased for all five cyclophanes as expected for $\mathrm{H}$-coupled chromophores due to a decrease of the radiative rate. For the three largest cyclophanes with interchromophoric distances of $>9 \AA$, fluorescence quantum yields remain high in chloroform $(>88 \%)$, whilst for the smaller ones with interchromophoric distances $<6 \AA$, additional nonradiative pathways lead to a pronounced fluorescence quenching.

Key words cyclophanes, exciton coupling, fluorescence, organic dyes

\section{Introduction}

Historically, the interest of chemists in cyclophanes was motivated by imparting strain in aromatic molecules such as [2.2]-paracyclophane, ${ }^{1}$ which were described by Cram as "internally tortured molecules with inherent suicidal tendencies." ${ }^{2}$ Later on, cyclophanes enjoyed increasing popularity in supramolecular chemistry with Stoddart's "blue box" cyclobis(paraquat-p-phenylene) as a most useful prototype due to its strong complexation of electron-rich aromatic guests such as dialkoxybenzenes, ${ }^{3}$ which in combination with the cyclophane's redox activity enabled the control of motion in catenanes and rotaxanes by electrical stimuli. ${ }^{4}$ However, despite the usefulness of cyclophane-based supramolecular host-guest complexes, ${ }^{5}$ progress in the expansion of the applicable $\pi$-scaffolds was slow-going. For instance, it took until 2013 before Stoddart and co-workers reported on the ExBox, bearing just one additional $p$-phenylene unit, and its interesting complexation properties for a variety of larger aromatic $\pi$ scaffolds. $^{6}$

More recently, cyclophanes demonstrated their usefulness for a variety of applications, which originate from the control of photofunctional properties. ${ }^{7}$ In such systems, two dyes are positioned in space by a suitable linker that determines the distance and orientation between the dyes and by this means their electronic coupling. Indeed, whilst covalent dimers of a variety of chromophores have become favored systems since several decades for the elucidation of dye-dye interactions in the ground and excited states, ${ }^{8}$ in earlier times often motivated by the special pair of chlorophylls in the photosynthetic reaction center, ${ }^{9}$ dyecontaining cyclophanes remained less investigated. ${ }^{10}$ This is at first glance surprising because cyclophanes can offer a good control of orientation and distance of the chromophores in rather rigid geometries, which is ideal for deriving structureproperty relationships and the supramolecular engineering of desirable functionality. ${ }^{11}$ However, in particular for chromophores with low solubility and strong aggregation propensity, such as those given for perylene bisimide (PBI) dyes, ${ }^{12}$ cyclophane synthesis can be quite challenging. Thus, it was only in 2015 that our group reported the first example for a PBI-based cyclophane (3b, Scheme 1) that was able to accommodate a variety of polycyclic aromatic hydrocarbons (PAHs) with high binding constants in its cavity. ${ }^{13}$ What distinguished cyclophane $\mathbf{3 b}$ from earlier PBI-based 
<smiles></smiles>

1<smiles>CC1(c2ccc(C#[Al+])cc2)CC1</smiles>

Linker<smiles>NCCCCCCCCN</smiles>

2a-e

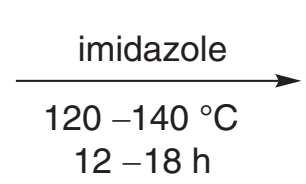

a: $19 \%$

b: $18 \%$

c: $19 \%$

d: $14 \%$

e: $10 \%$

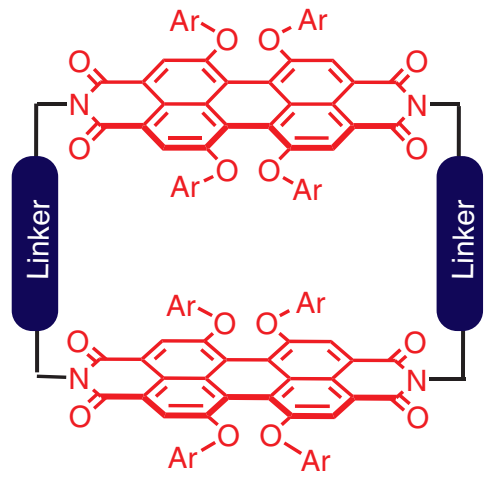

3a-e<smiles>Cc1cccc(C)c1</smiles>

a<smiles>Cc1ccc(I)cc1</smiles>

b<smiles>Cc1ccc(Cc2ccc(C)cc2)cc1</smiles>

c<smiles>Cc1ccc(-c2ccc(C)cc2)cc1</smiles>

d<smiles>Cc1ccc(-c2cccc(-c3ccc(C)cc3)c2)cc1</smiles>

e<smiles>COc1cc2c3c(cc(O[Al])c4c5c(O[Al])cc6c7c(cc(O[Al])c(c1c34)c75)C(=O)N(Cc1ccccc1)C6=O)C(=O)N(Cc1ccccc1)C2=O</smiles>

Ref-PBI

Scheme 1 Synthesis of PBI cyclophanes 3a-e starting from 1,6,7,12-tetra (tert-butylphenoxy)-substituted perylene bisanhydride $\mathbf{1}^{20}$ and the respective diamines $\mathbf{2 a - e}$. The synthesis of cyclophanes $\mathbf{3 b}$-e was performed in toluene to make use of the template effect. Also shown is the chemical structure of $\mathrm{PBI}$ chromophore Ref-PBI, ${ }^{13 a}$ which is used as a reference compound in this work.

cyclophanes ${ }^{14}$ was the cavity size that was just ideal for the inclusion of PAH guest molecules such as perylene. However, due to the strong propensity of PBIs for aggregation, ${ }^{15}$ it is not trivial to synthesize such cyclophanes and the number and type of phenoxy units in the bay area proved to be crucial. Thus, whilst a yield of $18 \%$ could be obtained for cyclophane $\mathbf{3 b}$ bearing four tert-butylphenoxy substituents, ${ }^{13}$ the yield in cyclophane synthesis dropped down to $<1 \%$ for the related twofold tert-butylphenoxy-substituted PBIs ${ }^{16}$ and could only raise up to $6 \%$ for those phenoxy groups bearing additional sterically demanding substituents in the ortho-position to prohibit PBI aggregation. ${ }^{17}$ These results corroborate our hypothesis that the strong $\pi-\pi$-stacking propensity of PBIs countervails the efficient synthesis of PBI cyclophanes bearing open cavities and that the core distortion of the PBI $\pi$-scaffold imposed by four phenoxy units in the bay area ${ }^{18}$ is highly supportive for the preparation of cyclophanes composed of PBIs. Based on this hypothesis, in this study we explore the synthesis of a series of tetraphenoxy-PBI cyclophanes 3a-e bearing different linker units (Scheme 1) with the particular goal of modulating the size of the $\pi$-cavity and deriving relationships between dye-dye distances and functional properties, i.e. fluorescence and exciton coupling.

\section{Results and Discussion}

\section{Synthesis}

The synthetic procedure of five PBI cyclophanes is shown in Scheme 1. Cyclophanes bearing meta-xylene $(\mathbf{3 a})^{19}$ and para-xylene $(\mathbf{3 b})^{13}$ linker moieties are known and the synthesis of cyclophanes 3c-e was performed under similar conditions. Accordingly, 1,6,7,12-tetra (tert-butylphenoxy)substituted perylene bisanhydride $\mathbf{1}^{20}$ was reacted with the respective diamines $\mathbf{2 a - e}$ in imidazole. For the synthesis of cyclophane $\mathbf{3 b}$, a significant increase of the yield was 
observed upon addition of toluene, which can be rationalized by a template effect. ${ }^{13 a}$ The addition of perylene, which showed a high binding constant for the encapsulation into cyclophane $\mathbf{3 b}$ in former studies, ${ }^{13 a}$ did not lead to an increase of the yield. Hence, the synthesis of the cyclophanes was performed in toluene at low concentration to avoid the formation of undesired oligomers. Notably, for PBI cyclophane 3a, bearing the shortest linker unit within the series (meta-xylene), no template effect was observed since the small cavity size (vide infra) prevents the enclosure of toluene molecules. Thus, 3a was obtained in decent yields of $19 \%$ without the addition of toluene (Scheme 1). Cyclophanes $\mathbf{3 a}$ and $\mathbf{3 b}$ were purified by column chromatography, whereas for cyclophanes $\mathbf{3 c}-\mathbf{e}$ recycling gel permeation chromatography as well as preparative thin layer chromatography (in the case of $\mathbf{3 c}$ ) was applied to separate nondesired oligomeric side-products and larger macrocycles. For details on the synthetic procedures and characterization of the new PBI cyclophanes, see the Experimental Section.

\section{Molecular Modeling}

In order to gain insight into the interchromophoric distances within the cyclophanes, geometry optimizations have been performed. Toward this goal, the semiempirical Hamiltonian PM6 ${ }^{21}$ was used as implemented in the MOPAC program package. ${ }^{22}$ In addition, the $\mathrm{D} 3 \mathrm{H} 4$ correction $^{23}$ was employed to also account for dispersion interactions. The geometry-optimized structures of PBI cyclophanes 3a-e are displayed in Figure 1. As expected, the cavity size increases with the length of the linker unit, ranging from $5.0 \AA$ (3a) to $12.5 \AA$ (3e). The tert-butylphenoxy groups in the bay position of the chromophores can cover a wide conformational space, ${ }^{18 a}$ which may lead to sterical encounters, thereby influencing the interchromophoric distances for the cyclophanes 3a-c with shorter linker moieties. Therefore, the distances given in Figure 1 are defined as the distance between the $\mathrm{CH}_{2}$ groups of the spacer units linked to the imide groups of the PBI chromophores, which should not be affected by the arrangement of the bay substituents.

Known for bay-substituted PBI dyes, ${ }^{18 a}$ the tert-butylphenoxy groups induce a twist of the naphthalene moieties of the perylene core leading to the presence of atropisomers, which can interconvert at room temperature. ${ }^{24}$ Since we are mainly interested in the dimensions of the cavities and in order to reduce computational effort, we have only minimized the structure of the homochiral pair for each cyclophane, i.e., $(P, P)$-configuration. In this way, a torsional twist of $\sim 27^{\circ}$ between the two naphthalimide subunits of each PBI is obtained for all cyclophanes, which is in good agreement with the values found in the solid state for fourfold phenoxysubstituted PBIs. ${ }^{18 a}$ It is worth noting that different con-

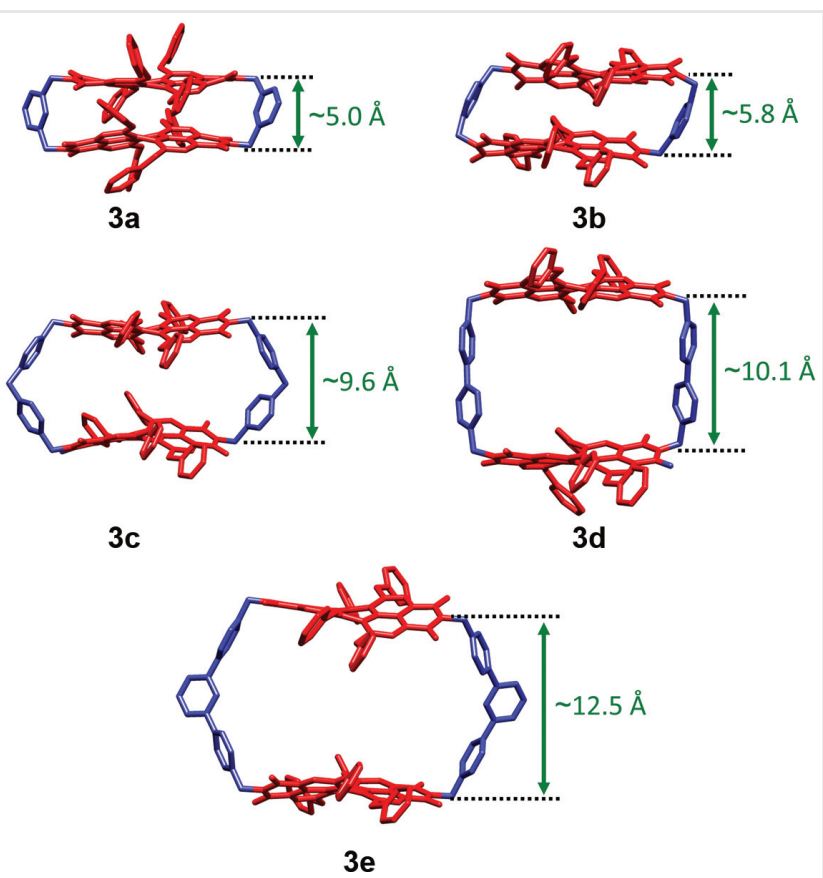

Figure 1 Geometry-optimized structures (PM6-D3H4) 21,23 of PBI cyclophanes 3a-e with increasing size of the linker. Hydrogen atoms and butyl groups are omitted for clarity. The PBI chromophores and linker moieties are colored in red and blue, respectively.

formations other than the ones shown in Figure 1 are present in solution. However, the linker moieties ensure a quite fixed distance of the PBI chromophores. Hence, the results obtained from geometry optimizations indeed show that the chosen linker moieties are suitable to modulate the cavity size and to ensure diverse interchromophoric distances.

\section{Single-Crystal X-Ray Structure}

In general, PBIs bearing four phenoxy substituents in the bay area are conformationally very flexible and not easy to pack in an ordered fashion in the crystalline state. Therefore, only few crystal structures are available for these molecules. ${ }^{25}$ For cyclophanes with large cavities, the situation is even more difficult as the crystal may collapse when the solvent diffuses out of the cavity. However, PBI cyclophane 3d bearing biphenylene linker units crystallized rather easily. Accordingly, single crystals of 3d suitable for X-ray diffraction analysis were obtained by slow diffusion of $n$-hexane into a solution of the cyclophane in chloroform. The molecule crystallizes in a $\mathrm{P} \overline{1}$ point group with one cyclophane moiety in the unitcell. Hence, the cyclophane shows an inversion center. Furthermore, the two PBI moieties of the cyclophane are coplanar in the solid state (Figure 2a) and are not rotationally displaced as observed for many stacked PBI chromophores. ${ }^{11}$ The distance between the carbon atoms of the $\mathrm{CH}_{2}$ groups of 


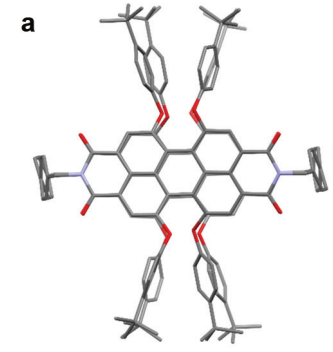

b

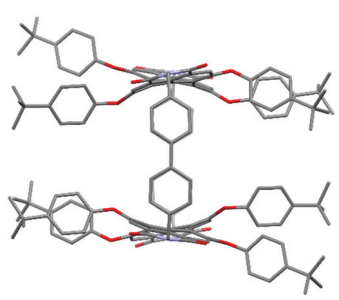

c

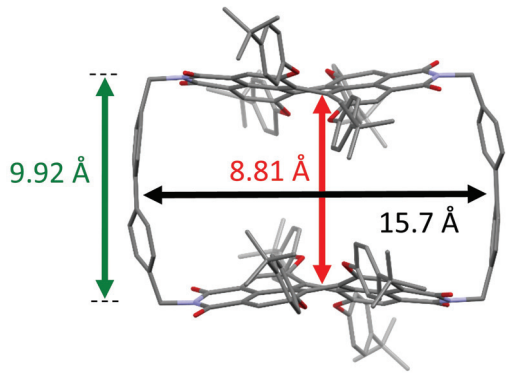

d

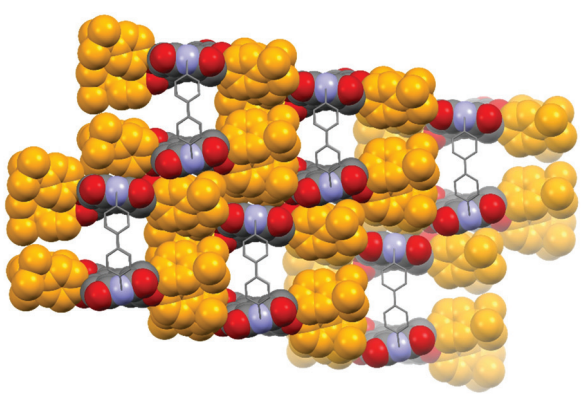

Figure 2 Molecular structure of cyclophane 3d found in single crystals in (a) top view, (b) front, and (c) side view. (d) In addition, the packing arrangement in the crystal is shown in front view. Hydrogen atoms are omitted for clarity. Carbon, oxygen, and nitrogen atoms are colored in grey, red, and violet, respectively. In panel (d), the PBI chromophores and tert-butylphenoxy groups (highlighted in orange) are displayed in a space-filling model.

the linker is $9.92 \AA$, which is in good agreement with the value of 10.1 Å obtained from geometry optimizations (Figure 1 ). The median distance between the carbon atoms of the central ring of the PBI moieties is reduced to $8.81 \AA$ (Figure 2c), caused by the slightly curved structure of the chromophores. The $\pi$-surfaces of the phenyl rings of the linker point towards the cavity with a distance of $15.7 \AA$.

The sterically demanding bay substituents point away from the cavity. Similar to other tetraphenoxy-substituted PBIs, ${ }^{25}$ the symmetry is broken, i.e., the phenoxy groups are oriented in different conformations at the two opposing bay areas. In the crystal, the cavity is filled with a heavily disordered solvent ( $n$-hexane), which was removed by the SQUEEZE routine in our crystallographic analysis. ${ }^{26}$ Interestingly, the crystal structure exclusively shows the heterochiral $(P, M)$-configuration, which might be preferred to enable a nonchiral space group in the crystal. The angle of torsional twist of the PBI moiety that is induced by the bulky bay substituents is about $29^{\circ}$, which is similar to those of monomeric fourfold phenoxy-substituted PBIs ${ }^{18 a}$ and again in good agreement with the value obtained from molecular modeling of $27^{\circ}$. Furthermore, the packing of the cyclophanes reveals that there is no $\pi-\pi$ stacking between adjacent cyclophanes (Figure 2d), which is probably due to the steric hindrance by the bulky bay substituents (highlighted in orange).

\section{UV/Vis Absorption and Fluorescence Spectroscopy}

Due to the fact that the transition dipole moment for the $\mathrm{S}_{0} \rightarrow \mathrm{S}_{1}$ transition of PBIs is oriented along the long molecular axis, ${ }^{11}$ these PBI cyclophanes with their exact linkercontrolled distances constitute ideal systems to elucidate interchromophoric interactions. Accordingly, the optical properties of the PBI cyclophanes were studied via UV/vis absorption and fluorescence spectroscopy. The respective data in chloroform are summarized in Table 1 in comparison to a monomeric reference compound, Ref-PBI. ${ }^{13 a}$ The UV/vis absorption spectrum of Ref-PBI in chloroform shows

Table 1 Absorption and fluorescence data of cyclophanes 3a-e and Ref-PBI in chloroform at $293 \mathrm{~K}$ (in addition, the exciton coupling strength $\int$ is given as estimated based on the absorption spectra)

\begin{tabular}{|c|c|c|c|c|c|c|}
\hline & $3 a$ & $3 \mathbf{b}^{13 a}$ & $3 c$ & $3 d$ & $3 e$ & Ref-PBI $^{13 a}$ \\
\hline$\lambda_{\text {abs }}\left(A_{0-0}\right) / \mathrm{nm}$ & 577 & 586 & 585 & 589 & 589 & 588 \\
\hline$\lambda_{\text {abs }}\left(A_{0-1}\right) / \mathrm{nm}$ & 541 & 547 & 546 & 549 & 548 & 547 \\
\hline$A_{0-0} / A_{0-1}$ & 1.12 & 1.25 & 1.45 & 1.48 & 1.56 & 1.66 \\
\hline $\begin{array}{l}\varepsilon_{\max }\left(A_{0-0}\right) \\
{\left[\mathrm{M}^{-1} \mathrm{~cm}^{-1}\right]}\end{array}$ & 66000 & 60000 & 70400 & 60000 & 71100 & 41000 \\
\hline $\begin{array}{l}\varepsilon_{\max }\left(A_{0-1}\right) \\
{\left[\mathrm{M}^{-1} \mathrm{~cm}^{-1}\right]}\end{array}$ & 59000 & 48000 & 48700 & 40400 & 45600 & 24700 \\
\hline$\lambda_{\mathrm{em}}[\mathrm{nm}]^{\mathrm{a}}$ & 627 & 631 & 622 & 626 & 626 & 620 \\
\hline$\Delta \tilde{\mathrm{v}}_{\text {stokes }}\left[\mathrm{cm}^{-1}\right]$ & 1382 & 1217 & 1017 & 1003 & 1003 & 878 \\
\hline$\Phi_{\mathrm{fl}}[\%]^{\mathrm{b}}$ & 9 & 21 & 88 & 93 & 94 & 97 \\
\hline $\begin{array}{l}T_{\mathrm{fl}}[\mathrm{ns}], \\
(\text { ampl./\%) }\end{array}$ & $\begin{array}{l}10.0 \\
(65) \\
0.72 \\
(35)\end{array}$ & $\begin{array}{l}12.5 \\
(68) \\
0.55 \\
(32)\end{array}$ & 8.2 & 7.8 & 7.2 & 6.5 \\
\hline$k_{\mathrm{f}}\left[10^{8} \mathrm{~s}^{-1}\right]^{\mathrm{d}}$ & 0.09 & 0.17 & 1.07 & 1.19 & 1.31 & 1.49 \\
\hline$k_{\mathrm{nr}}\left[10^{8} \mathrm{~s}^{-1}\right]^{\mathrm{d}}$ & 0.91 & 0.63 & 0.14 & 0.09 & 0.08 & 0.05 \\
\hline$J\left[\mathrm{~cm}^{-1}\right]^{\mathrm{e}}$ & 333 & 244 & 123 & 107 & 64 & - \\
\hline
\end{tabular}

aThe solutions were excited at the wavelength of the $0-1$ absorption band. ' The fluorescence quantum yields were measured relative to $N, N^{\prime}$-bis $(2,6$ diisopropylphenyl)-1,6,7,12-tetraphenoxy-3,4:9,10-perylene tetracarboxylic diimide ("Perylene Red") ${ }^{27}$ as a reference at four different excitation wavelengths.

${ }^{C}$ For lifetime measurements a pulsed laser diode with a wavelength of $505.8 \mathrm{~nm}$ was used.

${ }^{\mathrm{d}}$ Determined according to $k_{\mathrm{fl}}=\Phi_{\mathrm{fl}} / T_{\mathrm{fl}}$ and $k_{\mathrm{nr}}=1 / \tau_{\mathrm{fl}}-k_{\mathrm{fl}}$.

ealculated based on Equation (1). 


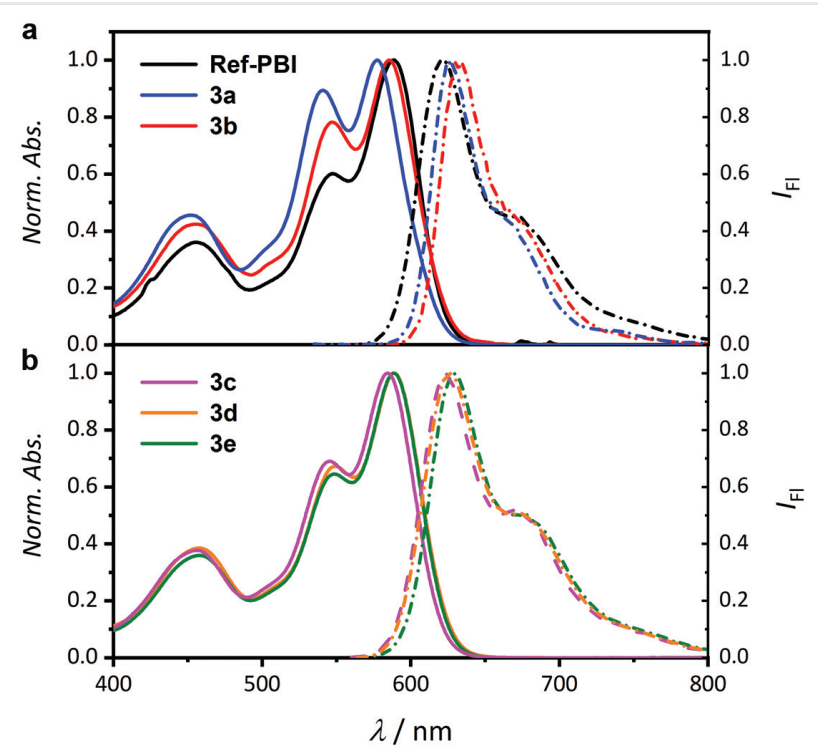

Figure 3 Normalized UV/vis absorption (solid lines, $c \approx 10^{-5} \mathrm{M}$ ) and fluorescence spectra (dash-dotted lines) of (a) Ref-PBI and PBI cyclophanes $\mathbf{3} \mathbf{a}, \mathbf{b}$ as well as of (b) $\mathbf{3} \mathbf{c}-\mathbf{e}$ in chloroform at $293 \mathrm{~K}$. For the detection of the fluorescence spectra, the samples were excited at the wavelength of the $0-1$ absorption band.

a typical pattern for PBIs with a pronounced vibronic fine structure (Figure 3a, black solid line). The main absorption band corresponding to the $S_{0} \rightarrow S_{1}$ transition is observed at $588 \mathrm{~nm}$ with a vibronic progression $\left(A_{0_{-}}\right)$at $547 \mathrm{~nm}$, whereas the absorption band at $\sim 450 \mathrm{~nm}$ occurs from the $\mathrm{S}_{0} \rightarrow \mathrm{S}_{2}$ transition. $^{27}$ In comparison to the monomeric reference dye, the absorption spectrum of cyclophane 3a with the shortest linker unit shows a significant redistribution of oscillator strength of the vibronic bands (Figure 3a, blue solid line). Accordingly, a decrease in the ratio $\left(A_{0-0} /\right.$ $\left.A_{0-1}\right)$ of the intensity of the $0-0$ and $0-1$ bands from 1.66 for Ref-PBI to 1.12 for PBI cyclophane $\mathbf{3 a}$ is observed (Figure 4a, filled squares). This is indicative of interchromophoric interaction between the chromophores in terms of exciton-vibrational coupling (H-type coupling). ${ }^{28}$ For better comparison of the $A_{0-0} / A_{0-1}$ ratios for the different cyclophanes, the spectra are normalized and shown in Figure 3 (for the spectra with extinction coefficients, see Figure S1 in the Supporting Information). In the case of cyclophane $\mathbf{3 b}$ bearing a slightly larger interchromophoric distance, the ratio $A_{0-0} / A_{0-1}=1.25$ is augmented (Figure 3a, red solid line) with respect to cyclophane 3a, revealing a weaker exciton coupling. For cyclophanes $\mathbf{3 c}-\mathbf{e}$, significantly larger $A_{0_{-} 0} / A_{0_{-}}$ratios are observed, ranging from 1.45 for cyclophane $3 \mathbf{c}$ to 1.56 for cyclophane $3 \mathbf{e}$ (Figures $3 \mathrm{~b}$ and $4 \mathrm{a}$ ). The latter value is only slightly lower than the one observed for Ref-PBI, indicating only a weak but still noticeable H-type coupling within the cyclophane $\mathbf{3 e}$. In the case of a $\pi$-stacked arrangement of the chromophores, we

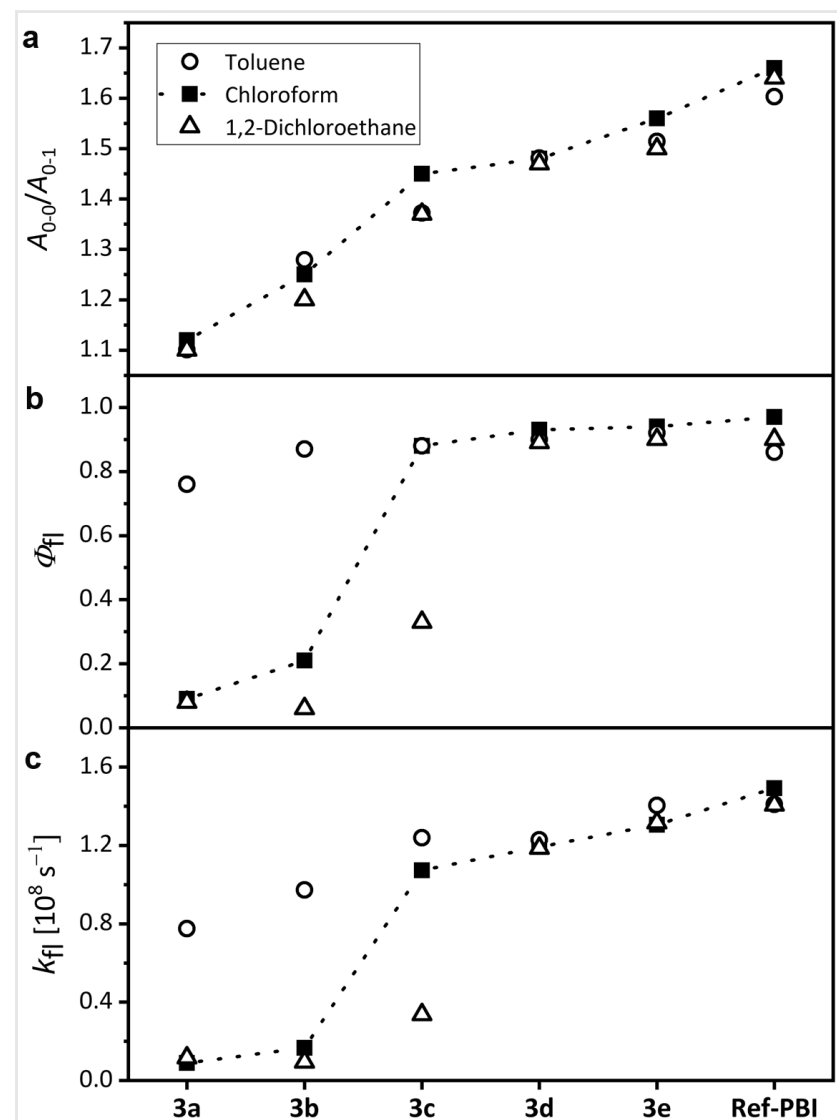

Figure 4 (a) Intensity ratio of the $0-0$ and $0-1$ absorption bands of PBI cyclophanes 3a-e and Ref-PBI in solvents of different polarity. In addition, (b) the fluorescence quantum yield $\Phi_{\mathrm{fl}}$ and (c) fluorescence rate constant $k_{\mathrm{fl}}$ are shown.

would expect a ratio of $A_{0-0} / A_{0-1} \approx 0.72,{ }^{29}$ which is distinctly smaller than the ratios observed for the PBI cyclophanes 3a-e. This suggests for all cyclophanes within this series that the cavity is open and a defined interchromophoric distance is present. Indeed, the ratio increases slightly within the series 3c-e (Figure 4a), which is in accordance with the expected increase of interchromophoric distance according to the geometry-optimized structures (Figure 1) and therefore decrease of interaction. Furthermore, the ratio $A_{0-0} / A_{0-1}$ is not significantly influenced by the polarity of the solvent (Figure 4a), revealing similar exciton coupling strength in the different solvents.

The fluorescence spectra of the cyclophanes in chloroform resemble the one of monomeric Ref-PBI (Figure 3, dash-dotted lines) with an increasing Stokes shift from $1,003 \mathrm{~cm}^{-1}$ (3e) to $1,382 \mathrm{~cm}^{-1}$ (3a) with decreasing length of the linker. This is in agreement with an augmented exciton coupling between the chromophores for shorter distances. Hence, a larger energetic splitting of the vibrational levels occurs that leads to an increased relaxation energy in the excited state. $^{28 b}$ For a perfect 
$\mathrm{H}$-aggregate, the $0-0$ fluorescence band is suppressed since the transition from the lowest excited state is forbidden. ${ }^{28 \mathrm{~b}}$ However, cyclophanes 3a-e all show an intense 0-0 emission band, which can be caused by a rotational displacement of the chromophores, ${ }^{30}$ thermal activation of higher allowed excited states, ${ }^{31}$ and/or by disorder, ${ }^{32}$ presumably arising from the conformational flexibility of the bay substituents. For cyclophanes $\mathbf{3 c - e}$ also the fluorescence quantum yields remain high (88-94\%), whilst the fluorescence quantum yields are significantly quenched for cyclophanes 3a and $\mathbf{3 b}$ (Table 1 and Figure 4b). As shown in previous work using time-resolved absorption spectroscopy, this decrease is not only caused by the H-type exciton coupling, but also by an additional relaxation pathway, i.e., symmetry-breaking charge separation, being favored for shorter interchromophoric distances. ${ }^{13 \mathrm{~b}, 19 \mathrm{~b}}$ This conclusion is supported by the observation that the fluorescence quantum yield is distinctly higher in solvents of lower polarity such as toluene (Figure $4 \mathrm{~b}$, open circles), in which the driving force for charge separation is reduced due to a less efficient stabilization of the charge-separated state. Notably, a significant drop of the fluorescence quantum yield is also observed for PBI cyclophane $\mathbf{3 c}$ in the more polar solvent 1,2-dichloroethane (Figure 4b, open triangles), indicating a competing photoinduced symmetry-breaking charge separation also in the case of $\mathbf{3 c}$ in this solvent.

We have also determined the fluorescence lifetime $\tau_{\mathrm{fl}}$ to gain deeper insight into the excited-state properties of the coupled chromophores. Accordingly, compared to $6.5 \mathrm{~ns}$ for Ref-PBI, an increase of the lifetime from $7.2 \mathrm{~ns}$ (3e) to $10.0 \mathrm{~ns}$ (3a) with decreasing interchromophoric distance can be observed (Table 1). This increase can be attributed to the H-type coupling between the PBI chromophores. With decreasing interchromophoric distance within this series of cyclophanes, H-type coupling increases (vide infra), thereby reducing the oscillator strength for the radiative process and the fluorescence decay rates $k_{\mathrm{fl}}$ with respect to the single chromophore of Ref-PBI (Table 1 and Figure 4c). Together with the measured fluorescence quantum yields, we can also calculate the rate constants $k_{\mathrm{nr}}$ for the nonradiative decay. Hence, the nonradiative relaxation remains slow for Ref-PBI and the larger cyclophanes but becomes significantly faster at short interchromophoric distances (Table 1), in agreement with the observation of an effective additional charge separation process between PBI chromophores lying in close spatial proximity. ${ }^{13 b, 19 b}$

It is worth noting that for the smallest cyclophanes $\mathbf{3 a}$ and $\mathbf{3 b}$, a biexponential fit had to be applied in order to describe the fluorescence decay, which results in a long- and a short-living component. This can be rationalized by the population of different conformations in the ground state enforced by the flexible phenoxy groups, ${ }^{18 a, 25}$ showing distinctly different fluorescence lifetimes upon excitation.

\section{Theoretical Investigations}

Exciton-vibrational coupling in PBI aggregates results in a redistribution of oscillator strength of the vibronic bands. ${ }^{28,30}$ The vibronic contribution arises from the coupling of the electronic $S_{0} \rightarrow S_{1}$ transition to the $C-C$ stretching mode of the PBI core, which causes the pronounced vibronic progression as observed in the absorption spectrum of the monomeric PBI chromophore Ref-PBI (Figure 3a, black line). For H-typecoupled dye aggregates, a decrease of the $A_{0_{-0}} / A_{0-1}$ ratio is observed, the magnitude of which depends on the exciton coupling strength. Hence, it is possible to determine the coupling strength based on the changes of the intensity of the $A_{0-0}$ band and an increase of the intensity of the $A_{0-1}$ band. In the weak coupling regime (i.e., exciton coupling is weaker than vibronic coupling), the ratio of the band intensities for two coupled oscillators in our cyclophane architecture is given by: ${ }^{30}$

$$
\frac{I_{\mathrm{A}}^{(0-0)}}{I_{\mathrm{A}}^{(0-1)}}=\frac{1}{\lambda^{2}}\left[\frac{1-G\left(0, \lambda^{2}\right) \mathrm{e}^{-\lambda^{2}} J / \omega_{0}}{1-G\left(1, \lambda^{2}\right) \mathrm{e}^{-\lambda^{2}} J / \omega_{0}}\right]^{2}
$$

where $\omega_{0}$ is the vibrational frequency and $\lambda^{2}$ the Huang-Rhys factor, which determine the strength of the vibronic coupling. In addition, $G\left(v_{\mathrm{t}}, \lambda^{2}\right)$ is the vibrational function and $J$ the exciton coupling strength. The Huang-Rhys factor $\lambda^{2}$ and vibrational frequency $\omega_{0}$ can be estimated from the intensity ratio and energetic difference of the $0-1$ and $0-0$ absorption bands $^{30}$ of the monomeric chromophore of Ref-PBI, respectively (for details see the Supporting Information). In this way, a value of $\lambda^{2}=0.59$ is obtained, in accordance with previously reported results for PBI chromophores. ${ }^{30,33}$ The resulting exciton coupling strengths are listed in Table 1. Hence, PBI cyclophane 3a with the shortest interchromophoric distance exhibits the strongest coupling $\left(J=333 \mathrm{~cm}^{-1}\right)$, while the weakest coupling $\left(J=64 \mathrm{~cm}^{-1}\right)$ is indeed present for cyclophane $\mathbf{3 e}$ with the largest cavity size. Notably, these values are all significantly smaller than the vibronic coupling strength $\left(\lambda^{2} \omega_{0}=787 \mathrm{~cm}^{-1}\right)$ in PBI cyclophanes 3a-e and thereby justify the application of Equation (1). Furthermore, the calculated exciton coupling strengths in the PBI cyclophanes 3a-e are distinctly smaller than the value determined for a $\pi$-stacked cyclophane bearing two tetraphenoxy-substituted PBI chromophores $\left(500 \mathrm{~cm}^{-1}\right)$ at a short interchromophoric distance of $\sim 3.8 \AA \AA^{34}$ Therefore, it is reasonable to assume an open cavity for all PBI cyclophanes with significantly larger distances. Figure 5 shows the exciton coupling strength as a function of the distance $r$ between the chromophores within the cyclophanes (filled squares). In addition, the results obtained by applying the point-dipole approximation (green line) are shown, which describe the exciton coupling as the Coulomb interaction between the transition dipole moments $\mu_{\text {eg }}$ of the chromophores: ${ }^{35}$ 


$$
J=\frac{\mu_{e g}^{2}}{4 \pi \varepsilon_{0} \varepsilon_{r} r^{3}}
$$

Equation (2) assumes a perfect $\mathrm{H}$-aggregate without any rotational displacement of the transition dipole moments. $\varepsilon_{0}$ and $\varepsilon_{r}$ are the vacuum permittivity and the relative permittivity of the solvent, respectively, while $r$ represents the center-to-center distance of the transition dipole moments of the chromophores. Hence, the coupling strength should scale with $1 / r^{3}$, which is in good agreement with the trend observed for PBI cyclophanes 3a-e (Figure 5). We have used a value of $\mu_{e g}=6.82 \mathrm{D}$ as estimated from the absorption spectrum of Ref-PBI (for details see Supporting Information). The results are rather striking since the applicability of the point-dipole approximation has been questioned for smaller interchromophoric distances in many previous studies in the last 50 years. $^{36}$

In Equation (2), we have used the permittivity of chloroform $\left(\varepsilon_{r}=4.81\right)$. This might be an oversimplification, because it is uncertain if an inclusion of the solvent molecules into the cavity of the smaller cyclophanes $\mathbf{3 a , b}$ occurs. Therefore, in the future we would like to shine light on this surprising outcome. In addition, a rotational twist motion of the chromophores along the axis defined by the centers of the PBI moieties can occur in solution. This will influence the exciton coupling strength, and thus, have an impact on the redistribution of oscillator strengths of the vibronic bands in the UV/vis absorption spectrum. ${ }^{30}$ Nonetheless, our studies reveal that the increasing exciton coupling with decreasing cavity size

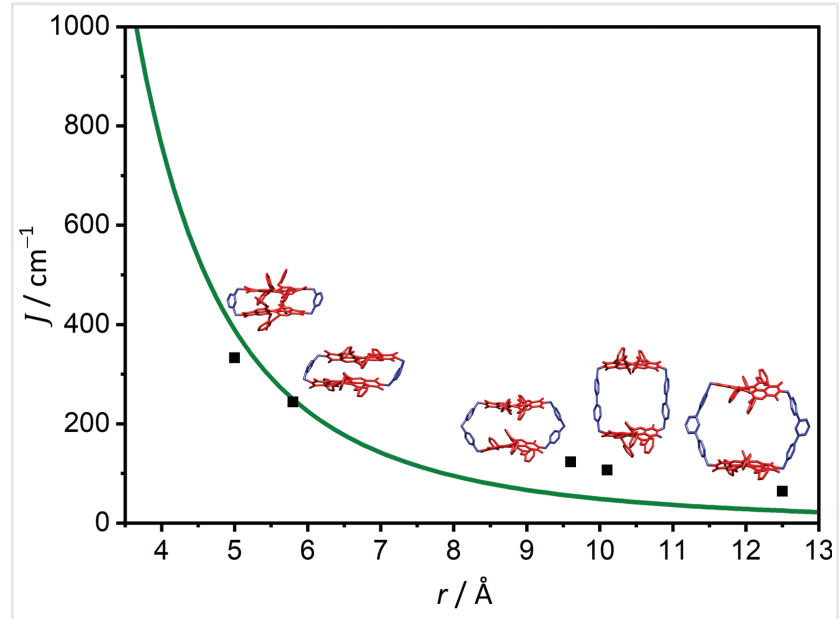

Figure 5 Exciton coupling strength / as a function of the interchromophoric distance $r$ within the series of PBI cyclophanes 3a-e. The filled squares represent the values determined based on Equation (1) using the absorption spectra in chloroform. In addition, the results obtained by applying the point-dipole approximation according to Equation (2) are shown as a green line. significantly affects the optical properties of the cyclophanes.

\section{Conclusions}

In conclusion, we have reported a series of cyclophane architectures bearing two PBI dyes at defined interchromophoric distances between 5.0 and 12.5 Å. Different from other covalently tethered dye dimers, ${ }^{8}$ the geometry in the cyclophanes 3a-e is exactly defined with regard to the interchromophoric distance and the coplanar orientation of the dyes' transition dipole moments. This allowed us to derive relationships between structure and optical properties (absorption, fluorescence) at an unrivaled accuracy. Thus, a monotonous increase in H-type exciton coupling strength from 64 to $333 \mathrm{~cm}^{-1}$ was observed with decreasing interchromophoric distance, leading to a decrease of the $A_{0-0} / A_{0-1}$ intensity ratio of the vibronic bands in absorption spectra, a decrease in fluorescence quantum yields and radiative rates, and an increasing Stokes shift. Whilst all of these observations are in accordance with Kasha's molecular exciton coupling theory and recent extensions by Spano, for the cyclophanes with the shortest linker units additional nonradiative decay processes were deduced from our analysis, which can be related to energetically favored symmetry-breaking charge separation processes. ${ }^{13 b, 19 b}$ Accordingly, our results demonstrate that cyclophane architectures are perfectly suited to derive unambiguous insights into interchromophoric interactions, because they allow positioning dyes at well-defined positions in space.

\section{Experimental Section}

\section{Procedures}

Chemicals and solvents were purchased from commercial suppliers (abcr GmbH, Alfa Aesar, Grüssing GmbH, Acros Organics, Fluorochem Ltd, Merck, Sigma-Aldrich, TCI Chemicals, and Fisher Scientific). Dry solvents were obtained from the purification system PS-M6-6/7-En from Inert Technologies.

Column chromatography was performed using standard glass columns of different sizes, packed with silica gel with a particle size of 40-63 $\mu \mathrm{M}$ purchased from Macherey-Nagel as a stationary phase. All solvents used for the column chromatography were distilled before use. Preparative thinlayer chromatography (TLC) was carried out with ALUGRAM ${ }^{\circledR}$ Xtra SIL G/UV254 (layer thickness: $0.2 \mathrm{~mm}$ ) TLC plates, purchased from Macherey-Nagel.

For gel permeation chromatography (GPC) purification, the preparative recycling GPC system LaboACE from Japan 
Analytical Industry Co., Ltd. (JAI) with PLgel Prep columns from Agilent Technologies (eluent: $\mathrm{CHCl}_{3} /$ methanol 9:1) was used.

All electrospray ionization (ESI) mass spectra were recorded on a micrOTOF focus spectrometer from Bruker Daltonics GmbH.

The melting points were determined using a polarization microscope BX41 from Olympus equipped with a TP-94 temperature regulation system from Linkam Scientific and are uncorrected.

All ${ }^{1} \mathrm{H}$ NMR and ${ }^{13} \mathrm{C}$ NMR spectra were recorded with an Avance III HD 400 spectrometer from Bruker operating at $400 \mathrm{MHz}\left({ }^{1} \mathrm{H}\right)$ or $101 \mathrm{MHz}\left({ }^{13} \mathrm{C}\right)$ or on a DMX 600 from Bruker operating at $600 \mathrm{MHz}\left({ }^{1} \mathrm{H}\right)$ or $151 \mathrm{MHz}\left({ }^{13} \mathrm{C}\right)$. Chemical shifts are listed in parts per million and are reported using the residual solvent signal as calibration standard. The multiplicities for proton signals are abbreviated as s, d, dd, t, and $\mathrm{m}$ for singlet, doublet, doublet of doublets, triplet, and multiplet.

UV-vis absorption spectra were measured with a V-770 spectrophotometer (Jasco) equipped with a JASCO PAC743R Auto Peltier 6/8-cell changer system for the temperature control. Standard quartz glass cuvettes (Hellma) and spectroscopy-grade chloroform, toluene, and 1,2-dichloroethane were used.

Fluorescence studies were carried out on an FLS980 spectrometer from Edinburgh Instruments. Standard quartz glass cuvettes from Hellma with a path length of $1 \mathrm{~cm}$ and spectroscopy-grade chloroform, toluene, and 1,2-dichloroethane were used. The fluorescence quantum yields $\left(\Phi_{\mathrm{fl}}\right)$ were determined as average values at four different excitation wavelengths $(520,525,530$, and $535 \mathrm{~nm})$ using $N, N$ '-(2,6-di-iso-propylphenyl)-1,6,7,12-tetraphenoxy-perylene-3,4:9,10-tetracarboxylic acid bisimide $\left(\Phi_{\mathrm{fl}}=96 \%\right.$ in chloroform $)^{26}$ as standard under highly diluted $(\mathrm{OD} \leq 0.05)$ and magic angle $\left(54.7^{\circ}\right)$ conditions. The fluorescence lifetimes were determined via time correlated single photon counting (TCSPC) using an EPL picosecond pulsed diode laser $\left(\lambda_{\mathrm{fl}}=505.8 \mathrm{~nm}\right)$ with a pulse width of $141.7 \mathrm{ps}$ with an FLS980-D2D2-ST spectrometer (Edinburgh Instruments Ltd., UK) under magic-angle conditions $\left(54.7^{\circ}\right)$. The fitting of the data was carried out using the Tail-Fit routine supplied by Edinburgh Instruments Ltd., Inc. For lifetimes $<3$ ns, the reconvolution fit routine supplied by Edinburgh Instruments Ltd., Inc. was used, taking the instrument response function into consideration.

\section{X-Ray Structure Analysis}

Single-crystal X-ray diffraction data for 3d were collected at $100 \mathrm{~K}$ on a Bruker D8 Quest Kappa diffractometer with a Photon100 CMOS detector and multilayered mirror monochromated $\mathrm{CuK}_{\alpha}$ radiation. The structure was solved using direct methods, expanded with Fourier techniques, and refined with the Shelx software package. ${ }^{37}$ All non-hydrogen atoms were refined anisotropically. Hydrogen atoms were included in the structure factor calculation on geometrically idealized positions. The refinement showed solvent molecules in the cavity of the cyclophanes, which could not be modeled satisfactorily. Therefore, the SQUEEZE routine of PLATON was used to remove the respective electron density. ${ }^{26}$ The remaining structure could be refined adequately. Crystal data for 3d $\left(\mathrm{C}_{156} \mathrm{H}_{136} \mathrm{~N}_{4} \mathrm{O}_{16}+\right.$ solvent $): \quad M_{\mathrm{r}}=2322.68$, red block, $0.096 \times 0.062 \times 0.056 \mathrm{~mm}^{3}$, triclinic space group $\mathrm{P} \overline{1}$, $a=15.1230(10) \AA, \alpha=102.166(3)^{\circ}, b=16.7031(11) \AA$, $\beta=100.936(3)^{\circ}, \quad c=16.5230(4) \AA, \quad \gamma=69.0340(10)^{\circ}$, $V=3712.3(4) \quad \AA^{3}, \quad Z=2, \quad \rho \quad$ (calcd. $)=1.039 \mathrm{~g} \mathrm{~cm}^{-3}$, $\mu=0.530 \mathrm{~mm}^{-1}, \quad F(000)=1228, \quad \operatorname{Goo} F\left(F^{2}\right)=1.074$, $R_{1}=0.0478, \quad w R^{2}=0.1302$ for $I>2 \sigma(I), \quad R_{1}=0.0583$, $w R^{2}=0.1374$ for all the data, 14534 unique reflections $\left(\theta \leq 72.396^{\circ}\right)$ with a completeness of $99.8 \%$ and 818 parameters, 6 restraints. Crystallographic data have been deposited with the Cambridge Crystallographic Data Centre as supplementary publication no. CCDC 1992950. This data can be obtained free of charge from the Cambridge Crystallographic Data Centre via www.ccdc.cam.ac.uk/data_request/cif.

\section{Synthesis}

The precursors meta- and para-xylylenediamine were commercially available, whereas 4,4'-bis(aminomethyl)biphenyl, ${ }^{38}$ bis(4-aminomethylphenyl)-methane, ${ }^{39}$ and $\left[1,1^{\prime}: 3^{\prime}, 1^{\prime \prime}\right.$ -terphenyl]-4,4"-dimethanamine ${ }^{40}$ were prepared according to literature-known procedures. The synthesis of $1,6,7,12-$ tetrakis-4-tert-butylphenoxyperylene-3,4:9,10-tetracarboxylic acid bisanhydride (1) is also described in the literature. ${ }^{20}$

\section{PBI Cyclophane (3a)}

Perylene bisanhydride 1 (100 mg, $102 \mu \mathrm{mol}, 1.0$ eq.), meta-xylylenediamine ( $14.0 \mathrm{mg}, 102 \mu \mathrm{mol}, 1.0 \mathrm{eq}$.$) , and$ imidazole $(2.0 \mathrm{~g})$ were stirred under a nitrogen atmosphere for $12 \mathrm{~h}$ at $140{ }^{\circ} \mathrm{C}$. After cooling to room temperature, $2 \mathrm{~N}$ $\mathrm{HCl}_{\mathrm{aq}}(200 \mathrm{~mL})$ was added and the solution subsequently extracted with dichloromethane. The organic solvent was removed under reduced pressure and the crude product purified by column chromatography (silica gel, DCM) to obtain pure cyclophane $\mathbf{3 a}$ as a red solid $(21.0 \mathrm{mg}$, $9.68 \mu \mathrm{mol}, \quad 19 \%) . \quad$ M.p. $>300{ }^{\circ} \mathrm{C} . \quad{ }^{1} \mathrm{H}-\mathrm{NMR} \quad\left(\mathrm{CDCl}_{3}\right.$, $600 \mathrm{MHz}, 295 \mathrm{~K}): \delta[\mathrm{ppm}]=8.14(\mathrm{~s}, 4 \mathrm{H}), 7.99(\mathrm{~s}, 4 \mathrm{H})$, $7.55(\mathrm{~m}, 2 \mathrm{H}), 7.47\left(\mathrm{dd},{ }^{4} J(\mathrm{H}, \mathrm{H})=1.4 \mathrm{~Hz},{ }^{3} J(\mathrm{H}, \mathrm{H})=7.7 \mathrm{~Hz}\right.$, $4 \mathrm{H}), 7.33\left(\mathrm{~d},{ }^{3} \mathrm{~J}(\mathrm{H}, \mathrm{H})=8.6 \mathrm{~Hz}, 8 \mathrm{H}\right), 7.20\left(\mathrm{t},{ }^{3} \mathrm{~J}(\mathrm{H}\right.$, $\mathrm{H})=7.7 \mathrm{~Hz}, 2 \mathrm{H}), 7.10\left(\mathrm{~d},{ }^{3} \mathrm{~J}(\mathrm{H}, \mathrm{H})=8.6 \mathrm{~Hz}, 8 \mathrm{H}\right), 7.01\left(\mathrm{~d},{ }^{3} \mathrm{~J}\right.$ $(\mathrm{H}, \mathrm{H})=8.6 \mathrm{~Hz}, 8 \mathrm{H}), 6.35\left(\mathrm{~d},{ }^{3} \mathrm{~J}(\mathrm{H}, \mathrm{H})=8.6 \mathrm{~Hz}, 8 \mathrm{H}\right), 5.61(\mathrm{~d}$, $\left.{ }^{3} J(\mathrm{H}, \mathrm{H})=13.5 \mathrm{~Hz}, 4 \mathrm{H}\right), 4.81\left(\mathrm{~d},{ }^{3} \mathrm{~J}(\mathrm{H}, \mathrm{H})=13.5 \mathrm{~Hz}, 8 \mathrm{H}\right)$, 
1.38 (s, $36 \mathrm{H}), 1.25$ (s, $36 \mathrm{H}) .{ }^{13} \mathrm{C}-\mathrm{NMR}\left(\mathrm{CDCl}_{3}, 151 \mathrm{MHz}\right.$, $295 \mathrm{~K}): \delta[\mathrm{ppm}]=163.1,156.5,154.2,153.9,152.4147 .5$, $147.0,137.4,132.9,131.4,130.7,127.8,127.0,126.8,123.0$, $122.5,121.7,121.5,119.6,119.5,119.1,118.3,43.2,34.6$, $34.5,31.7,31.5$. Two signals were not observed due to overlap with other signals. HRMS (ESI, positive mode): $m / z=2169.94021[\mathrm{M}+\mathrm{H}]^{+}$(calcd. for $\mathrm{C}_{144} \mathrm{H}_{129} \mathrm{~N}_{4} \mathrm{O}_{16}{ }^{+}$: 2169.93981). UV/vis $\left(\mathrm{CHCl}_{3}, c=50 \mu \mathrm{M}\right): \lambda_{\mathrm{abs}}[\mathrm{nm}]\left(\varepsilon_{\max }\right.$, $\left.\left[\mathrm{M}^{-1} \mathrm{~cm}^{-1}\right]\right)=577$ (66000), 541 (59000), 451 (30100). Fluorescence $\left(\mathrm{CHCl}_{3}\right): \lambda_{\mathrm{em}}[\mathrm{nm}]\left(\lambda_{\mathrm{ex}}[\mathrm{nm}]\right)=627$ (530), $\operatorname{PLQY}\left(\mathrm{CHCl}_{3}\right): \Phi_{\mathrm{fl}}[\%]=9$.

\section{PBI Cyclophane (3c)}

Perylene bisanhydride 1 (90.0 mg, $91.4 \mu \mathrm{mol}, 1.0$ eq.), bis(4-aminomethylphenyl)methane $(20.7 \mathrm{mg}, 91.4 \mu \mathrm{mol}$, 1.0 eq.), and imidazole ( $1.35 \mathrm{~g}$ ) were suspended in dry toluene $(250 \mathrm{~mL})$. The reaction mixture was stirred at $120^{\circ}$ $\mathrm{C}$ for $18 \mathrm{~h}$. The mixture was allowed to cool down to room temperature and the solvent was removed under reduced pressure. The residue was dissolved in chloroform $(50 \mathrm{~mL})$ and washed with $1 \mathrm{~N} \mathrm{HCl}_{\mathrm{aq}} .(2 \times 100 \mathrm{~mL})$ and water $(100 \mathrm{~mL})$. The organic phase was dried over $\mathrm{MgSO}_{4}$ and the solvent was evaporated. The crude product was purified by filtration through a silica plug (DCM) and recycling GPC (chloroform/MeOH 9:1) to give 3c as a red solid (20.4 mg, $8.68 \mu \mathrm{mol}, 19 \%)$. M.p. $>300{ }^{\circ} \mathrm{C} .{ }^{1} \mathrm{H}-\mathrm{NMR}\left(1,1,2,2-\mathrm{C}_{2} \mathrm{D}_{2} \mathrm{Cl}_{4}\right.$, $400 \mathrm{MHz}, 390 \mathrm{~K}): \delta[\mathrm{ppm}]=8.18(\mathrm{~s}, 8 \mathrm{H}), 7.36\left(\mathrm{~d},{ }^{3} \mathrm{~J}=7.8\right.$ $\mathrm{Hz}, 8 \mathrm{H}), 7.23\left(\mathrm{~d},{ }^{3} \mathrm{~J}=8.6 \mathrm{~Hz}, 16 \mathrm{H}\right), 7.09\left(\mathrm{~d},{ }^{3} \mathrm{~J}=7.8 \mathrm{~Hz}, 8 \mathrm{H}\right)$, $6.83\left(\mathrm{~d},{ }^{3} \mathrm{~J}=8.6 \mathrm{~Hz}, 16 \mathrm{H}\right), 5.24(\mathrm{~s}, 8 \mathrm{H}), 3.93(\mathrm{~s}, 4 \mathrm{H}), 1.34$ (s, 72H). ${ }^{13} \mathrm{C}-\mathrm{NMR}\left(1,1,2,2-\mathrm{C}_{2} \mathrm{D}_{2} \mathrm{Cl}_{4}, 151 \mathrm{MHz}, 360 \mathrm{~K}\right): \delta$ $[\mathrm{ppm}]=163.1,155.7,152.6,147.3,139.8,134.6132 .7$, 128.8, 128.7, 126.3, 122.1, 120.5, 119.7, 119.2, 119.1, 43.2, 34.1, 31.3, 29.5. HRMS (ESI, positive mode): $\mathrm{m} / \mathrm{z}=$ 1197.49862 $\left[\mathrm{M}+\mathrm{Na}_{2}\right]^{2+}$ (calcd. for $\mathrm{C}_{158} \mathrm{H}_{140} \mathrm{~N}_{4} \mathrm{Na}_{2} \mathrm{O}_{16}{ }^{2+}$ : $m / z=1197.50244)$. UV/vis $\left(\mathrm{CHCl}_{3}, c=10 \mu \mathrm{M}\right): \lambda_{\mathrm{abs}}[\mathrm{nm}]$ $\left(\varepsilon_{\max },\left[\mathrm{M}^{-1} \mathrm{~cm}^{-1}\right]\right)=585$ (70400), 546 (48700), $458(25600)$. Fluorescence $\left(\mathrm{CHCl}_{3}\right): \lambda_{\mathrm{em}}[\mathrm{nm}]\left(\lambda_{\mathrm{ex}}[\mathrm{nm}]\right)=622(546)$. PLQY $\left(\mathrm{CHCl}_{3}\right): \Phi_{\mathrm{fl}}[\%]=88$.

\section{PBI Cyclophane (3d)}

Perylene bisanhydride 1 (90.0 mg, $91.4 \mu \mathrm{mol}, 1.0$ eq.), 4,4'-bis(aminomethyl)biphenyl (18.5 mg, $91.4 \mu \mathrm{mol}, 1.0$ eq.), and imidazole (1.35 g) were suspended in dry toluene $(250 \mathrm{~mL})$. The reaction mixture was stirred at $120{ }^{\circ} \mathrm{C}$ for $18 \mathrm{~h}$. The mixture was allowed to cool down to room temperature and the solvent was removed under reduced pressure. The residue was dissolved in chloroform $(50 \mathrm{~mL})$ and washed with $1 \mathrm{~N} \mathrm{HCl}_{\mathrm{aq}}(2 \times 100 \mathrm{~mL})$ and water $(100 \mathrm{~mL})$. The organic phase was dried over $\mathrm{MgSO}_{4}$ and the solvent was evaporated. The crude product was purified by filtration through a silica plug (DCM), recycling GPC (chloroform/MeOH 9:1), and preparative TLC (silica gel,
DCM/cyclohexane 2:1) to give $\mathbf{3 d}$ as a red solid (15.3 $\mathrm{mg}$, $6.59 \mathrm{mmol}, 14 \%)$. M.p. $>300{ }^{\circ} \mathrm{C} .{ }^{1} \mathrm{H}-\mathrm{NMR}\left(1,1,2,2-\mathrm{C}_{2} \mathrm{D}_{2} \mathrm{Cl}_{4}\right.$, $400 \mathrm{MHz}, 360 \mathrm{~K}): \delta[\mathrm{ppm}]=8.17(\mathrm{~s}, 8 \mathrm{H}), 7.48\left(\mathrm{~d},{ }^{3} \mathrm{~J}=8.4\right.$ $\mathrm{Hz}, 8 \mathrm{H}), 7.41\left(\mathrm{~d},{ }^{3} \mathrm{~J}=8.4 \mathrm{~Hz}, 8 \mathrm{H}\right), 7.25\left(\mathrm{~d},{ }^{3} \mathrm{~J}=8.7 \mathrm{~Hz}, 16 \mathrm{H}\right)$, $6.82\left(\mathrm{~d},{ }^{3} \mathrm{~J}=8.7 \mathrm{~Hz}, 16 \mathrm{H}\right), 5.36(\mathrm{~s}, 8 \mathrm{H}), 1.35$ (s, 72H). ${ }^{13} \mathrm{C}-$ $\operatorname{NMR}\left(1,1,2,2-\mathrm{C}_{2} \mathrm{D}_{2} \mathrm{Cl}_{4}, 151 \mathrm{MHz}, 352 \mathrm{~K}\right): \delta[\mathrm{ppm}]=162.8$, 155.6, 152.7, 147.3, 139.3, 136.5, 132.5, 129.6, 126.5, 126.4, 120.4, 120.2, 119.9, 119.2,119.0, 42.7, 34.1, 31.3. HRMS (ESI, positive mode): $m / z=2343.97555[\mathrm{M}+\mathrm{Na}]^{+}$(calcd. for $\left.\mathrm{C}_{156} \mathrm{H}_{136} \mathrm{~N}_{4} \mathrm{NaO}_{16}{ }^{+}: \quad m / z=2343.98435\right)$. UV/vis $\left(\mathrm{CHCl}_{3}\right.$, $c=10 \mu \mathrm{M}): \lambda_{\mathrm{abs}}[\mathrm{nm}]\left(\varepsilon_{\max },\left[\mathrm{M}^{-1} \mathrm{~cm}^{-1}\right]\right)=589(60000)$, 549 (40400), 458 (23100). Fluorescence $\left(\mathrm{CHCl}_{3}\right): \lambda_{\mathrm{em}}[\mathrm{nm}]$ $\left(\lambda_{\mathrm{ex}}[\mathrm{nm}]\right)=626$ (549). PLQY $\left(\mathrm{CHCl}_{3}\right): \Phi_{\mathrm{fl}}[\%]=93$.

\section{PBI Cyclophane (3e)}

Perylene bisanhydride 1 ( $80.0 \mathrm{mg}, 81.2 \mu \mathrm{mol}, 1.0$ eq.), [1,1':3',1'-terphenyl]-4,4"-dimethanamine (23.4 mg, $81.2 \mu \mathrm{mol}, 1.0$ eq.), and imidazole (1.35 g) were suspended in dry toluene $(250 \mathrm{~mL})$. The reaction mixture was stirred at $120{ }^{\circ} \mathrm{C}$ for $18 \mathrm{~h}$. Subsequently, the mixture was allowed to cool down to room temperature and the solvent was removed under reduced pressure. The residue was dissolved in chloroform $(50 \mathrm{~mL})$ and washed with $1 \mathrm{~N} \quad \mathrm{HCl}_{\mathrm{aq}}$. $(2 \times 100 \mathrm{~mL})$ and water $(100 \mathrm{~mL})$. The organic phase was dried over $\mathrm{MgSO}_{4}$ and the solvent was evaporated. The crude product was purified by filtration through a silica plug (DCM) and recycling GPC (chloroform/MeOH, 9:1) to give $3 \mathbf{e}$ as a red solid (10.2 mg, $4.12 \mu \mathrm{mol}, 10 \%)$. M.p. $>300{ }^{\circ} \mathrm{C}$. ${ }^{1} \mathrm{H}-\mathrm{NMR}$ $\left(\mathrm{CDCl}_{3}, 400 \mathrm{MHz}, 295 \mathrm{~K}\right): \delta[\mathrm{ppm}]=8.23(\mathrm{~s}, 8 \mathrm{H}), 7.55-7.42$ $(\mathrm{m}, 24 \mathrm{H}), 7.19\left(\mathrm{~d},{ }^{3} \mathrm{~J}=8.8 \mathrm{~Hz}, 16 \mathrm{H}\right), 6.78\left(\mathrm{~d},{ }^{3} \mathrm{~J}=8.8 \mathrm{~Hz}, 16 \mathrm{H}\right)$, $5.34\left(\mathrm{~s}, 8 \mathrm{H}, \mathrm{CH}_{2}\right), 1.26(\mathrm{~s}, 72 \mathrm{H}) .{ }^{13} \mathrm{C}-\mathrm{NMR}\left(\mathrm{CDCl}_{3}, 101 \mathrm{MHz}\right.$, $295 \mathrm{~K}): \delta[\mathrm{ppm}]=163.6,156.2,152.8,147.5,141.5,140.5$, 136.3, 133.0, 129.2, 128.9, 127.5, 126.8, 126.3, 125.9, 122.4, 120.7, 120.1, 119.6, 119.5, 43.6, 34.5, 31.6. HRMS (ESI, positive mode): $m / z=1259.51616\left[\mathrm{M}+\mathrm{Na}_{2}\right]^{2+}$ (calcd. for $\mathrm{C}_{168} \mathrm{H}_{144} \mathrm{~N}_{4} \mathrm{Na}_{2} \mathrm{O}_{16}{ }^{2+}:$ 1259.51809).UV/vis $\left(\mathrm{CHCl}_{3}, \mathrm{c}=10 \mu \mathrm{M}\right)$ : $\lambda_{\mathrm{abs}}[\mathrm{nm}]\left(\varepsilon_{\max },\left[\mathrm{M}^{-1} \mathrm{~cm}^{-1}\right]\right)=589(71100), 548(45600), 457$ (26700). Fluorescence $\left(\mathrm{CHCl}_{3}\right): \lambda_{\mathrm{em}}[\mathrm{nm}]\left(\lambda_{\mathrm{ex}}[\mathrm{nm}]\right)=626$ (548). PLQY $\left(\mathrm{CHCl}_{3}\right): \Phi_{\mathrm{fl}}[\%]=94$.

\section{Funding Information}

The authors are grateful for financial support from the Deutsche Forschungsgemeinschaft (DFG) within the research training school GRK 2112 on "Molecular Biradicals" at the University of Würzburg.

\section{Supporting Information}

Supporting information for this article is available online at https://doi.org/10.1055/s-0040-1709998. 


\section{References}

(1) Steinberg, H.; Cram, D. J. J. Am. Chem. Soc. 1952, 74, 5388.

(2) Cram, D. J.; Cram, J. M. Acc. Chem. Res. 1971, 4, 204.

(3) Odell, B.; Reddington, M. V.; Slawin, A. M.Z.; Spencer, N.; Stoddart, J. F.; Williams, D. J. Angew. Chem. Int. Ed. 1988, 27, 1547.

(4) Stoddart, J. F. Angew. Chem. Int. Ed. 2017, 56, 11094.

(5) (a) Diederich, F. Angew. Chem. Int. Ed. 1988, 27, 362. (b) Liu, Z.; Nalluri, S. K. M.; Stoddart, J. F. Chem. Soc. Rev. 2017, 46, 2459.

(6) (a) Barnes, J. C.; Juríček, M.; Strutt, N. L.; Frasconi, M.; Sampath, S.; Giesener, M. A.; McGrier, P. L.; Bruns, C. J.; Stern, C. L.; Sarjeant, A. A.; Stoddart, J. F. J. Am. Chem. Soc. 2013, 135, 183. (b) Dale, E. J.; Vermeulen, N. A.; Juríček, M.; Barnes, J. C.; Young, R. M.; Wasielewski, M. R.; Stoddart, J. F. Acc. Chem. Res. 2016, 49, 262.

(7) Spenst, P.; Würthner, F. J. Photochem. Photobiol., A 2017, 31, 114.

(8) (a) Giaimo, J. M.; Gusev, A. V.; Wasielewski, M. R.J. Am. Chem Soc. 2002, 124, 8530. (b) Vauthey, E. ChemPhysChem 2012, 13, 2001. (c) Bartynski, A. N.; Gruber, M.; Das, S.; Rangan, S.; Mollinger, S.; Trinh, C.; Bradforth, S. E.; Vandewal, K.; Salleo, A.; Bartynski, R. A.; Bruetting, W.; Thompson, M. E. J. Am. Chem. Soc. 2015, 137, 5397. (d) Bialas, D.; Kirchner, E.; Würthner, F. Chem. Commun. 2016, 52, 3777. (e) Sung, J.; Nowak-Król, A.; Schlosser, F.; Fimmel, B.; Kim, W.; Kim, D.; Würthner, F. J. Am. Chem. Soc. 2016, 138, 9029. (f) Hetzer, C.; Guldi, D. M.; Tykwinski, R. R. Chem. Eur. J. 2018, 24, 8245. (g) Papadopoulos, I.; Zirzlmeier, J.; Hetzer, C.; Bae, Y. J.; Krzyaniak, M. D.; Wasielewski, M. R.; Clark, T.; Tykwinski, R. R.; Guldi, D. M. J. Am. Chem. Soc. 2019, 141, 6191.

(9) (a) Wasielewski, M. R. Chem. Rev. 1992, 92, 435. (b) Maruyama, K.; Osuka, A.; Mataga, N. Pure Appl. Chem. 1994, 66, 867.

(10) (a) Keshri, S. K.; Takai, A.; Ishizuka, T.; Kojima, T.; Takeuchi, M. Angew. Chem. Int. Ed. 2020, 59, 5254. (b) Adinarayana, B.; Kato, K.; Shimizu, D.; Tanaka, T.; Furukawa, K.; Osuka, A. Angew. Chem. Int. Ed. 2020, 59, 4320. (c) Zwick, P.; Weiland, K. J.; Malinčík, J.; Stefani, D.; Häussinger, D.; van der Zant, H. S. J.; Dulić, D.; Mayor, M. J. Org. Chem. 2020, 85, 118. (d) Nozawa, R.; Kim, J.; Oh, J.; Lamping, A.; Wang, Y. M.; Shimizu, S.; Hisaki, I.; Kowalczyk, T.; Fliegl, H.; Kim, D.; Shinokubo, H. Nat. Commun. 2019, 10, 3576.

(11) Würthner, F.; Saha-Möller, C. R.; Fimmel, B.; Ogi, S.; Leowanawat, P.; Schmidt, D. Chem. Rev. 2016, 116, 962.

(12) Chen, Z.; Lohr, A.; Saha-Möller, C. R.; Würthner, F. Chem. Soc. Rev. 2009, 38, 564.

(13) (a) Spenst, P.; Würthner, F. Angew. Chem. Int. Ed. 2015, 54, 10165. (b) Spenst, P.; Young, R. M.; Wasielewski, M. R.; Würthner, F. Chem. Sci. 2016, 7, 5428.

(14) (a) Langhals, H.; Ismael, R. Eur.J. Org. Chem. 1998, 1915. (b) Feng, J.; Zhang, Y.; Zhao, C.; Lamping, A.; Wang, Y. M.; Shimizu, S.; Hisaki, I.; Kowalczyk, T.; Fliegl, H.; Kim, D.; Shinokubo, H. Chem. Eur. J. 2008, 14, 7000. (c) Schlosser, F.; Moos, M.; Lambert, C.; Würthner, F. Adv. Mater. 2013, 25, 410. (d) Ball, M.; Zhong, Y.; Fowler, B.; Zhang, B.; Li, P.; Etkin, G.; Paley, D. W.; Decatur, J.; Dalsania, A. K.; Li, H.; Xiao, S.; Ng, F.; Steigerwald, M. L.; Nuckolls, C. J. Am. Chem. Soc. 2016, 138, 12861.
(15) Chen, Z.; Fimmel, B.; Würthner, F. Org. Biomol. Chem. 2012, 10, 5845.

(16) Sieblist, A. Bachelor thesis. Universität Würzburg; 2014.

(17) Spenst, P.; Sieblist, A.; Würthner, F. Chem. Eur. J. 2017, 23, 1667.

(18) (a) Würthner, F. Pure Appl. Chem. 2006, 78, 2341. (b) NowakKról, A.; Würthner, F. Org. Chem. Front. 2019, 6, 1272.

(19) (a) Spenst, P. PhD thesis. Universität Würzburg; 2016. (b) Schultz, J. D.; Coleman, A. F.; Mandal, A.; Shin, J. Y.; Ratner, M. A.; Young, R. M.; Wasielewski, M. R. J. Phys. Chem. Lett. 2019, 10, 7498.

(20) Würthner, F.; Thalacker, C.; Sautter, A.; Schärtl, W.; Ibach, W.; Hollricher, O. Chem. Eur. J. 2000, 6, 3871.

(21) Stewart, J. J. P. J. J. Mol. Model. 2007, 13, 1173.

(22) (a) MOPAC2012. Stewart, J. J. P. Stewart Computational Chemistry, Version 14.045, web: http://OpenMOPAC.net. (b) Maia, J. D. C.; Urquiza Carvalho, G. A.; Mangueira, C. P. Jr; Santana, S. R.; Cabral, L. A. F.; Rocha, G. B. J. Chem. Theory Comput. 2012, 8, 3072.

(23) Řezáč, J.; Hobza, P. J. Chem. Theory Comput. 2012, 8, 141.

(24) Osswald, P.; Würthner, F. J. Am. Chem. Soc. 2007, 129, 14319.

(25) (a) Osswald, P.; Leusser, D.; Stalke, D.; Würthner, F. Angew. Chem. Int. Ed. 2005, 44, 250. (b) Hippius, C.; van Stokkum, I. H. M.; Zangrando, E.; Williams, R. M.; Wykes, M.; Beljonne, D.; Würthner, F. J. Phys. Chem. 2008, 112, 14626.

(26) Spek, A. L. Acta Crystallogr. A 1990, 46, C34.

(27) (a) Seybold, G.; Wagenblast, G. Dyes Pigm. 1989, 11, 303.(b) Gvishi, R.; Reisfeld, R.; Burshtein, Z. Chem. Phys. Lett. 1993, 213, 338.

(28) (a) Seibt, J.; Winkler, T.; Renziehausen, K.; Dehm, V.; Würthner, F.; Meyer, H. D.; Engel, V. J. Phys. Chem. A 2009, 113, 13475. (b) Spano, F. C. Acc. Chem. Res. 2010, 43, 429.

(29) Schlosser, F.; Moos, M.; Lambert, C.; Würthner, F. Adv. Mater. 2013, 25, 410.

(30) Kistler, K. A.; Pochas, C. M.; Yamagata, H.; Matsika, S.; Spano, F. C. J. Phys. Chem. B 2012, 116, 77.

(31) Oleson, A.; Zhu, T.; Dunn, I. S.; Bialas, D.; Bai, Y.; Zhang, W.; Dai, M.; Reichman, D. R.; Tempelaar, R.; Huang, L.; Spano, F. C. J. Phys. Chem. C 2019, 123, 20567.

(32) Hestand, N. J.; Spano, F. C. Chem. Rev. 2018, 118, 7069.

(33) Kaufmann, C.; Bialas, D.; Stolte, M.; Würthner, F.J. Am. Chem. Soc. 2018, 140, 9986

(34) Bialas, D.; Brüning, C.; Schlosser, F.; Fimmel, B.; Thein, J.; Engel, V.; Würthner, F. Chem. Eur. J. 2016, 22, 15011.

(35) Kasha, M.; Rawls, H. R.; El-Bayoumi, M. A. Pure Appl. Chem. 1965, $11,371$.

(36) (a) Czikklely, V.; Forsterling, H. D.; Kuhn, H. Chem. Phys. Lett. 1970, 6, 207. (b) Beljonne, D.; Cornil, J.; Silbey, R.; Millié, P.; Brédas, J-L. J. Chem. Phys. 2000, 112, 4749. (c) Kistler, K. A.; Spano, F. C.; Matsika, S. J. Phys. Chem. B 2013, 117, 2032.

(37) Sheldrick, G. M. Acta Crystallogr. A 2008, 64, 112.

(38) Pascu, M.; Ruggi, A.; Scopelliti, R.; Severin, K. Chem. Commun. 2013, 49, 45.

(39) Rosa, J. C.; Galanakis, D.; Ganellin, C. R.; Dunn, P. M.; Jenkinson, D. H. J. Med. Chem. 1998, 41, 2.

(40) Rajakumar, P.; Padmanabhan, R. Tetrahedron 2011, 67, 9669. 